\title{
EFFECTS OF LUMBAR SNAG AND MECHANICAL TRACTION IN PATIENTS WITH DISCOGENIC LUMBOSACRAL RADICULOPATHY
}

\author{
Muzammal Ahmed, Naveed Anwar*, Sana Tauqeer**, Kehkshan Khalid*, Hammad Shakeel*** \\ Shalimar Hospital, Lahore Pakistan, *Riphah University, Lahore Pakistan, **Punjab Medical Complex, Lahore Pakistan, \\ ***Muhammadi Medical Trust Hospital, Lahore Pakistan
}

\begin{abstract}
Objective: To compare the effects of lumbar sustained natural apophyseal glide and Mechanical Traction in patients with discogenic lumbosacral radiculopathy.

Study Design: Quasi experimental study.

Place and Duration of Study: Kanaan Physiotherapy and Spine Clinic, from Mar to Sep 2020.

Methodology: A total of 44 patients were included in study in 2 groups of 22 each. Patients between ages 30-60 years having chronic radiating pain in one or both legs, patients with minimum of 25 score out of 100, on low back pain index and patients having radiculopathy were included. Exclusion criteria were history of low back pain treatment in last 90 . Complications such as cancer, spine pathology and joint disease. Dice roll method was used for group allocation. Group classification was as group 1, sustained natural apophyseal glide group, and group 2, mechanical traction group. NPRS and oswestry disability index were used. Data analysis was done with SPSS version 21.

Results: There is statistically significant improvement in pain as mean post treatment value for sustained natural apophyseal glide group is $2.55 \pm 1.503$ and for mechanical traction group is $4.05 \pm 1.864$, oswestry disability index and shober test results in sustained natural apophyseal glide group were also significant as compared to mechanical traction with $p$-value $<0.05$. Although pain was also decreased in mechanical traction group patients but overall sustained natural apophyseal glides were more effective.

Conclusion: Sustained natural apophyseal glide are more effective in the treatment of lumber radiculopathy patients as compared to mechanical traction. Further studies can be carried out to see the combination of these techniques to have better effects.
\end{abstract}

Keywords: Discogenic, Lumber, Radiculopathy, Traction.

This is an Open Access article distributed under the terms of the Creative Commons Attribution License (https://creativecommons.org/licenses/by-nc/4.0/), which permits unrestricted use, distribution, and reproduction in any medium, provided the original work is properly cited.

\section{INTRODUCTION}

Lumbosacral radiculopathy is common form of lower back pain and hip and it moves from backside of thigh and goes downward into leg1,2. Lower back pain is affecting many people from general population but lumbar radiculopathy affect $3-5 \%$ of population ${ }^{3}$. The compression of nerve roots can cause numbness, tingling, downward going pain and sometimes sharp shooting pain 4 . Radiculopathy is different from nerve root pain or radicular pain ${ }^{5}$.

Mulligan mobilization techniques are quite helpful in treating lumber radiculopathy. Lumber Sustained natural apophyseal glide (SNAG's) are very useful to relieve back pain ${ }^{6,7}$. Posistional SNAG's can alleviate symptoms in a single session as compared to other treatment options ${ }^{8}$. Mechanical traction is an effective way to alleviate the radiating pain in legs because of lumber radiculopathy ${ }^{9}$. Sustained Mechanical traction is more effective than manual traction as it is easy to

Correspondence: Dr Naveed Anwar, House No. 36-D, Street No. 4, Bhagpanpura, Lahore Pakistan

Received: 01 Feb 2021; revised received: 25 Mar 2021; accepted: 30 Mar 2021 apply for long time ${ }^{10}$.

Due to advance researches and evidence, role of physiotherapy has been proven the most effective one for long term and short-term effects. It is the question of importance to find out best technique among different manual therapy approaches. This study was an effort in to see if mechanical traction or SNAGs have any advantage over each other in treating lumber radiculopathy in patients of low back pain.

\section{METHODOLOGY}

This quasi-experimental study was conducted at Kanaan Physiotherapy and Sine Clinic, from March to September 2020. Non probability convenience sampling was used. Sample size was calculated through Epitool software by taking mean values (group A mean: 6.3 \& group B: 8.2) from previous study 9 . A total of 44 Patients were included in study in 2 groups of 22 each. Participants were included fulfilling following criteria. Both male and female patients between ages 30-60 years having chronic radiating pain in one or both legs were included. Patients having history of low back ache for 30 days in last six months. Minimum of 25 score out of 100, on low back pain index. Radiculo- 
pathy will be basis for inclusion or further screening. Participants were excluded in case of history of low back pain treatment in last 90 days or having contraindication to spinal manipulative therapy. Complications such as cancer, spine pathology, joint disease (inflammatory), disorders of autoimmune nature, neurodegenerative diseases, organic referred pain, pregnancy, and disability compensation. Patients were evenly distributed to two groups by using dice roll method of randomization. Group classification was as group 1, SNAG group, and group 2, mechanical traction group. It was a single blinded study. Only assessors were blinded. The physiotherapist and the patients were not blinded. Ethics approval was taken from Kanaan Physiotherapy and Spine Clinic Lahore, Pakistan. Outcome measure were Oswestry Disability Index ${ }^{12}$, Back pain through NPRS. Schober tests ${ }^{13}$, PSS windows software, version 21 was used for the analysis of data. Statistical significance was set at $p=0.05$. Following statistics were applied. Descriptive statistics (frequency distribution, mean and standard deviation) was used for the summary of measurements of groups and represented by frequency tables, histogram and bar charts. To compare mean difference of the outcome variables between two groups, Independent sample t-test was applied. To see difference at pre and post level among two group separately, paired sample t-test was applied. $p \leq 0.05$ was considered significant. Data was normally distributed. QQ plots were used to assess the normality of all variables. QQ plots showed that pre and post variables were normally distributed with $p$-value $>0.05$.

\section{RESULTS}

Baseline values of socio-demographic data of both groups were comparable on the basis of mean and standard deviation shown in the tables of demographic data of the participants which showed that baseline values for both groups are not different. The mean age of SNAG group was $47.86 \pm 9.829$ years while mean age for Mechanical traction group was $47.09 \pm 9.566$ years. The mean height of SNAG group was $163.64 \pm$ $13.482 \mathrm{~m}$ while mean height of mechanical traction group was $166.45 \pm 10.070 \mathrm{~m}$. The mean weight of SNAG group was $82.32 \pm 16.255 \mathrm{~kg}$ while mean weight of mechanical traction group was $76.91 \pm 14.826 \mathrm{~kg}$. The mean NPRS pre-treatment value for SNAG group was $6.64 \pm 1.590$ and for mechanical traction group was $5.32 \pm 1.673$ while post treatment value for SNAG group was $2.55 \pm 1.503$ and for mechanical traction group was $4.05 \pm 1.864$ (table-I). The mean ODI pretreatment value for SNAG group was $68.68 \pm 14.548$ and for mechanical traction group was $57.73 \pm 18.749$ while post treatment value for SNAG group was 26.05 \pm 14.411 and for mechanical traction group was $45.64 \pm$ 19.8769 (table-II). The mean shober test score pretreatment value for SNAG group was $4.164 \pm 0.6359$ and for mechanical traction group was $5.036 \pm 0.6138$ while post treatment value for SNAG group was $5.34 \pm$ 0.501 and for mechanical traction group was $5.232 \pm$ 0.3859 (table-III).

\section{DISCUSSION}

The study compares the efficacy of SNAGs and mechanical traction in patients with lumber radiculopathy. The results of the study showed that there is significant improvement in pain, Oswestry disability index and shober test results in SNAG group as compared to mechanical traction. Although pain was also decreased in mechanical traction group patients but overall SNAGs were more effective.

Table-I: Across group comparison of numeric pain rating scale (NPRS).

\begin{tabular}{|c|c|c|c|c|}
\hline & \multicolumn{2}{|c|}{ Treatment Groups } & \multirow[b]{2}{*}{$p$-value } \\
\hline & & $\begin{array}{c}\text { Sustained Natural } \\
\text { Apophyseal Glide (SNAG) }\end{array}$ & Mechanical Traction & \\
\hline \multirow{2}{*}{$\begin{array}{l}\text { Pain At numeric pain } \\
\text { rating scale }\end{array}$} & Pre Treatment $($ Mean \pm SD $)$ & $6.64 \pm 1.590$ & $5.32 \pm 1.673$ & 0.011 \\
\hline & Post Treatment (Mean \pm SD ) & $2.55 \pm 1.503$ & $4.05 \pm 1.864$ & 0.005 \\
\hline
\end{tabular}

Table-II: Across group comparison of oswestry disability index score.

\begin{tabular}{|c|c|c|c|c|}
\hline & & \multicolumn{2}{|c|}{ Treatment Groups } & \multirow[b]{2}{*}{$p$-value } \\
\hline & & $\begin{array}{c}\text { Sustained Natural } \\
\text { Apophyseal Glide (SNAG) }\end{array}$ & Mechanical Traction & \\
\hline \multirow{2}{*}{$\begin{array}{l}\text { Oswestry disability } \\
\text { index score (ODI) score }\end{array}$} & Pre Treatment (Mean \pm SD ) & $68.68 \pm 14.548$ & $57.73 \pm 18.749$ & 0.01 \\
\hline & Post Treatment (Mean \pm SD ) & $26.05 \pm 14.411$ & $45.64 \pm 19.769$ & 0.005 \\
\hline \multicolumn{5}{|c|}{ Table-III: Across group comparison of shober test score. } \\
\hline & & \multicolumn{2}{|c|}{ Treatment Groups } & \multirow[b]{2}{*}{$p$-value } \\
\hline & & $\begin{array}{c}\text { Sustained Natural } \\
\text { Apophyseal Glide (SNAG) }\end{array}$ & Mechanical Traction & \\
\hline \multirow{2}{*}{ Shober Test Score } & Pre Treatment (Mean \pm SD ) & $4.164 \pm 0.6359$ & $5.036 \pm 0.6138$ & 0.02 \\
\hline & Post Treatment (Mean \pm SD ) & $5.341 \pm 0.5011$ & $5.232 \pm 0.3859$ & 0.004 \\
\hline
\end{tabular}


The current study demonstrated the relief of pain was achieved in patients who underwent SNAG treatment with significant difference in pretreatment mean and post treatment mean. Moreover, patients who received mechanical traction showed improvement in pretreatment mean and post treatment mean. The improvement in pain was seen in both groups but there was more improvement in SNAG group. The results of this study are in accordance with the study done by Bhat et al. They saw the effects of spinal mobilization in lumber radiculopathy and results were in accordance with our study. There was significant improvement in pain with $p$-value $<0.055^{14}$.

Another study was conducted by Filiz et al. Both groups improved significantly in the NPRS, Oswesty Disability Index and modified lumbar Schober test as in current study. SNAG was found to be more effective as far as mean value is concerned ${ }^{15}$. It was found that If the lumber traction is added to other treatments in back pain patients then it can improve pain, disability and functional independence and studies show that traction applied in prone position can be of more value for relieving the symptoms. Although more studies are required to see the long term effects of lumber traction in prone position. There was no additional treatment given to the subjects in this study ${ }^{16}$.

A study conducted by Kumar et al finds out the combined effect of lumber traction, SNAGS and Neurodynamics in radiculopathy patients to improve pain and disability. Significant early improvements were noted in pain, range of motion and functional abilities in patients who received combined treatment. NPRS value decreased as in current study ${ }^{17}$.

The results of this study showed that the SNAG treatment is an effective means to reduce disability in patients with lumber radiculopathy. Minor effectiveness of mechanical traction can also be noted. The results of this study are supported by another study done by hidalgo et al, which showed that lumbar spine SNAGs had a short-term favorable effect on pain, disability and function in patients with nonspecific low back pain ${ }^{18}$.

The results of this study showed significant improvement in Shober test scores. Minimum improvement was seen in mechanical traction group and marked improvement was seen in SNAG group. The studies in support of this result cannot be found in literature specifically in lumber radiculopathy. A lot of work is being done in cervical region. SNAG treatment is an effective way to improve lumber ranges. These results were supported by another study done by which concluded that adding SNAG to routine physical therapy programs while treating chronic non-specific LBP may help out in early improvement of pain, positioning error and function ${ }^{19}$.

\section{CONCLUSION}

Sustained natural apophyseal glides are more affecting in treatment of pain and disability in lumber radiculopathy patients. Both groups showed improvement but these were more noteworthy in SNAG group.

\section{CONFLICT OF INTEREST}

This study has no conflict of interest to be declared by any author.

\section{REFERENCES}

1. Berry JA, Elia C, Saini HS, Miulli DE. A Review of Lumbar Radiculopathy, Diagnosis, and Treatment. Cureus 2019; 11(10): e5934-e38.

2. Satpute K, Hall T, Bisen R, Lokhande P. The effect of spinal mobilization with leg movement in patients with lumbar radiculopathy-a double-blind randomized controlled trial. Arch Phys Med Rehabi 2019; 100(5): 828-36.

3. Hussien HM, Abdel-Raoof NA, Kattabei OM, Ahmed HH. Effect of mulligan concept lumbar SNAG on chronic nonspecific low back pain. J Chiropr Med 2017; 16(2): 94-102.

4. Kuijer PPFM, Verbeek JH, Seidler A, Ellegast R, Hulshof CTJ, Frings-Dresen MHW, et al. Work-relatedness of lumbosacral radiculopathy syndrome. Neurol 2018; 91(12): 558-62.

5. Hartley RA, Kordecki ME. Rehabilitation of chronic brachial plexus neuropraxia and loss of cervical extension in a high school football player: a case report. Int J Sports Phys Ther 2018; 13(6): 1061-65.

6. Rasmussen K. The use of manual lumbar traction and therapeutic exercise in the treatment of a patient with low back pain: a case report. BMC Musculoskelet Disord 2017; 46(3): 45-47.

7. Zegarra-Parodi R, Park PYS, Heath DM, Makin IRS, Degenhardt BF. Assessment of skin blood flow following spinal manual therapy: a systematic review. Man Ther 2015; 20(2): 228-49.

8. Andrews DP, Odland-Wolf KB, May J, Baker R, Nasypany A, Dinkins EM. Immediate and short-term effects of mulligan concept positional sustained natural apophyseal glides on an athletic young-adult population classified with mechanical neck pain: an exploratory investigation. J Man Manip Ther 2018; 26(4): 203-11.

9. Bilgilisoy Filiz M, Kilic Z, Uckun A, Cakir T, Koldas Dogan S, Toraman NF. Mechanical traction for lumbar radicular pain: supine or prone? a randomized controlled trial. Am J Phys Med Rehabil 2018; 97(6): 433-39.

10. Khan S, Al Torairi N, Shamsi S. Comparative Study Of Snags And Maitland's Mobilization In Chronic Low Back Pain. Eur J Sport Sci 2018; 4(12): 32-34.

11. Isner-Horobeti ME, Dufour SP, Schaeffer M, Sauleau E, Vautravers $\mathrm{P}$, Lecocq J, et al. High-force versus low-force lumbar traction in acute lumbar sciatica due to disc herniation: a preliminary randomized trial. J Manipulative Physiol Ther 2016; 39(9): 645-54.

12. Fairbank JC, Pynsent PB. The Oswestry disability index. Spine 2000; 25(22): 2940-53.

13. Tousignant M, Poulin L, Marchand S, Viau A, Place C. The Modified-Modified Schober Test for range of motion assessment of lumbar flexion in patients with low back pain: A study of 
criterion validity, intra-and inter-rater reliability and minimum metrically detectable change. Disabil Rehabil 2005; 27(10): 553-59.

14. Bhat V, Patel VD, Eapen C, Shenoy M, Milanese S. Myofascial release versus Mulligan sustained natural apophyseal glides' immediate and short-term effects on pain, function, and mobility in non-specific low back pain. Peer J 2021; 9(1): e10706.

15. Ye C, Ren J, Zhang J, Wang C, Liu Z, Li F, et al. Comparison of lumbar spine stabilization exercise versus general exercise in young male patients with lumbar disc herniation after 1 year of follow-up. Int J Clin Exp Med 2015; 8(6): 9869-75.

16. Filiz MB, Kiliç Z, Uçkun A, Çakir T, Dogan SK, Toraman NF, et al. Mechanical traction for lumbar radicular pain: Supine or prone? a randomized controlled trial. Am J Phys Med Rehabil
2018; 97(6): 433-39.

17. Anandkumar $\mathrm{S}$. The effect of sustained natural apophyseal glide (SNAG) combined with neurodynamics in the management of a patient with cervical radiculopathy: a case report. Physiother Theory Pract 2015; 31(2): 140-45.

18. Hidalgo B, Pitance L, Hall T, Detrembleur C, Nielens H. Shortterm effects of Mulligan mobilization with movement on pain, disability, and kinematic spinal movements in patients with nonspecific low back pain: a randomized placebo-controlled trial. J Manipulative Physiol Ther 2015; 38(6): 365-74.

19. Manzoor T, Arshad N, Nasir N, Zia A. Effect of modified lumbar-sustained natural apophyseal glides (Snags) in nonspecific low back pain. Saudi J Sports Med 2019; 19(3): 86. 